\title{
The Glycoform Modifications of sRAGE Matter
}

\author{
Hyun-Jin Tae, Edward G Lakatta and Li Lin* \\ Laboratory of Cardiovascular Sciences, National Institute on Aging, NIH, Baltimore, MD, USA
}

The signaling of Receptors for Advanced Glycation End Products (RAGE) results in inflammation and tissue remodeling, and has been implicated in several human diseases, including cardiovascular disease [1-3]. Soluble RAGE (sRAGE) encompassing the entire ectoportion of RAGE, but lacking the membrane anchor and cytosolic signaling domain, functions as a decoy that counteracts RAGE-mediated inflammatory signaling by competing for RAGE ligands and dampening the subsequent inflammation and tissue remodeling [4]. RAGE/sRAGE is known to be modified by $\mathrm{N}$-linked glycosylation at two locations of the ligand binding $\mathrm{V}$ ectodomain [5], and such modification has been shown to be important for RAGE bioactivity [6,7]. Recombinant sRAGE has been generated and tested in several disease models in mice [8-10] or rats [11], and the results have shown a promise for future clinical applications. However, in these studies, recombinant sRAGE was produced in the fall armyworm (Spodoptera frugiperda) cell line sf9 via a baculovirus vector [8-11], rather than in mammalian source, making immunogenicity as well as bioactivity an issue.

Although glycoproteins expressed in insect and mammalian cells are both glycosylated, their glycoforms are different. Insect cells predominantly produce paucimannose $\mathrm{N}$-glycans, whereas mammalian cells can produce highly diverse $\mathrm{N}$-glycoforms including paucimannose, hybrid, and most often, complex type of glycans [12]. These different forms of post-translational modification may impact a therapeutic glycoprotein in the following aspects.

First, glycoforms act as antigens in vivo. Insect cell-originated $\mathrm{N}$-glycoforms are immunogenic in mammalian system. Currently, major regulatory authorities (FDA, EMEA) require that therapeutic glycoproteins to be produced in mammalian cell lines such as Chinese Hamster Ovary (CHO) cells and Human Embryonic Kidney cells (HEK293), or in mammalian sources via transgenic animals to avoid adverse side-effects and biosafety concerns [13].

Second, glycoforms contribute to bioactivities or in vivo duration of a glycoprotein, directly affecting its therapeutic efficacy [14]. A typical example is recombinant human Erythropoietin (EPO), a therapeutic glycoprotein used for the treatment of anemia-associated diseases. Proper glycosylation significantly enhances EPO bioactivity and duration of action in vivo [15]. Other examples include recombinant TNK-tissue plasminogen activator [16], and Soluble Intercellular Adhesion Molecule-1 (sICAM-1) [17].

Although direct evidence regarding $\mathrm{N}$-glycoform modifications and sRAGE in vivo efficacy is still lacking, results from several studies have shown that $\mathrm{N}$-glycoform modifications may contribute to RAGE signaling capacity and sRAGE activity in vitro. Genetic studies have shown that patients with a G82S polymorphism in AGER (the gene encoding RAGE) are prone to the development of diabetes [6]. Subsequent biochemical studies demonstrated that this polymorphism enhances RAGE N-glycosylation at residue N81, and affects RAGE signal transduction [7]. Since RAGE and sRAGE share the ectodomains, it can be inferred that sRAGE with proper $\mathrm{N}$-glycoform modifications may interact with RAGE ligands more effectively, and thus has higher blocking capacity. Indeed, earlier studies have also shown that sRAGE purified form animal lung tissues is more effective than that of sf9 cell- originated sRAGE to block RAGE ligand-induced vascular smooth cell migration in vitro. Recently, Srikrishna and colleagues showed that a small portion of sRAGE from lung tissue, modified by carboxylated $\mathrm{N}$-glycoforms, has higher bioactivity to block NF- $\mathrm{kB}$ in vitro than that of sRAGE produced in sf9 cells [18]. These studies support the general concept that a proper $\mathrm{N}$-glycoform modification is critical for a glycoprotein's bioactivity and therapeutic efficacy also applies to sRAGE.

Furthermore, the reported dosage of sf 9 cell-originated sRAGE is relatively high, i.e. $100 \mu \mathrm{g} / \mathrm{mouse} /$ day for mice [8-10], or $0.5 \mathrm{mg} / \mathrm{kg}$ body weight for rats [11]. In addition, either mouse or rat models used for blocking studies required daily sRAGE administration to achieve desired therapeutic outcomes. These suggest that the bioactivity of sf9 cell-originated recombinant sRAGE is relatively low. Significantly, a recent report showing that a similar dose of sf9 cell-originated sRAGE ( $5 \mu \mathrm{g} / \mathrm{g}$ body weight, assuming an average lab mouse weighs $20 \mathrm{~g}$ ) elicits monocyte inflammatory reactions in mice [19]. This observation further begs the question of whether it is apt to use sf9 cell-originated, rather than the mammalian cell-originated sRAGE with proper N-glycoform modifications in animal studies.

In our opinion, the specific N-glycoform modification of sRAGE matters. Systematic studies of the bioactivity and assessment of the in vivo efficacy of mammalian cell-originated recombinant sRAGE in animal models will test this concept. Information gleaned from these studies will render a more adequate assessment of sRAGE's therapeutic potential, including possible reduction of administrated dosage and administration frequency, owing to higher bioactivity and/or in vivo efficacy that are resulted from using a proper N-glycoform modified form. These studies will also provide a basis for further development of sRAGE as a candidate pharmacological glycoprotein for future clinical applications.

\section{Acknowledgements}

Our work is supported entirely by the Intramural Research Program of $\mathrm{NIH}$, National Institute on Aging.

\section{References}

1. Park S, Yoon SJ, Tae HJ, Shim CY (2011) RAGE and cardiovascular disease Front Biosci 16: 486-497.

2. Ramasamy R, Schmidt AM (2012) Receptor for advanced glycation end products (RAGE) and implications for the pathophysiology of heart failure. Curr Heart Fail Rep 9: 107-116.

*Corresponding author: Li Lin, Laboratory of Cardiovascular Sciences, National Institute on Aging, NIH, Baltimore, MD21224, USA, E-mail: linli@mail.nih.gov

Received July 26, 2013; Accepted July 26, 2013; Published July 30, 2013

Citation: Tae HJ, Lakatta EG, Lin L (2013) The Glycoform Modifications of sRAGE Matter. Cardiol Pharmacol 2: e114. doi:10.4172/2329-6607.1000e114

Copyright: (c) 2013 Tae HJ, et al. This is an open-access article distributed under the terms of the Creative Commons Attribution License, which permits unrestricted use, distribution, and reproduction in any medium, provided the original author and source are credited. 
3. Yan SF, Ramasamy R, Schmidt AM (2012) The RAGE axis: a fundamental mechanism signaling danger to the vulnerable vasculature. Circ Res 106: 842853.

4. Lin L, Park S, Lakatta EG (2009) RAGE signaling in inflammation and arterial aging. Front Biosci 14: 1403-1413.

5. Neeper M, Schmidt AM, Brett J, Yan SD, Wang F, et al. (1992) Cloning and expression of a cell surface receptor for advanced glycosylation end products of proteins. J Biol Chem 267: 14998-15004.

6. Kankova K, Zahejsky J, Marova I, Muzik J, Kuhrova V, et al. (2001) Polymorphisms in the RAGE gene influence susceptibility to diabetesassociated microvascular dermatoses in NIDDM. J Diabetes Complications 15 : 185-192.

7. Park SJ, Kleffmann T, Hessian PA (2011) The G82S polymorphism promotes glycosylation of the receptor for advanced glycation end products (RAGE) at asparagine 81: comparison of wild-type rage with the G82S polymorphic variant. J Biol Chem 286: 21384-21392.

8. Bucciarelli LG, Wendt T, Qu W, Lu Y, Lalla E, et al. (2002) RAGE blockade stabilizes established atherosclerosis in diabetic apolipoprotein E-null mice. Circulation 106: 2827-2835.9.

9. Park L, Raman KG, Lee KJ, Lu Y, Ferran LJ Jr, et al. (1998) Suppression of accelerated diabetic atherosclerosis by the soluble receptor for advanced glycation endproducts. Nat Med 4: 1025-1031.

10. Sakaguchi T, Yan SF, Yan SD, Belov D, Rong LL, et al. (2003) Central role of RAGE-dependent neointimal expansion in arterial restenosis. J Clin Invest 111 959-972.
11. Zhou Z, Wang K, Penn MS, Marso SP, Lauer MA, et al. (2003) Receptor for AGE (RAGE) mediates neointimal formation in response to arterial injury Circulation 107: 2238-2243.

12. Varki A, Cummings R, Esco J, Freeze H, Hart G, et al. (2009) Essentials of glycobiology. 2nd edition, Cold Spring Harbor Laboratory Press, Cold Spring Harbor, New York, USA.

13. Ghaderi D, Zhang M, Hurtado-Ziola N, Varki A (2012) Production platforms for biotherapeutic glycoproteins. Occurrence, impact, and challenges of nonhuman sialylation. Biotechnol Genet Eng Rev 28: 147-175.

14. Werner RG, Kopp K, Schlueter M (2007) Glycosylation of therapeutic proteins in different production systems. Acta Paediatr Suppl 96: 17-22.

15. Elliott S, Lorenzini T, Asher S, Aoki K, Brankow D, et al. (2003) Enhancement of therapeutic protein in vivo activities through glycoengineering. Nat Biotechnol 21: $414-421$

16. Jiang H, Wu SL, Karger BL, Hancock WS (2011) Characterization of the glycosylation occupancy and the active site in the follow-on protein therapeutic: TNK-tissue plasminogen activator. Anal Chem 82: 6154-6162.

17. Otto VI, Schurpf T, Folkers G, Cummings RD (2004) Sialylated complex-type $\mathrm{N}$-glycans enhance the signaling activity of soluble intercellular adhesion molecule-1 in mouse astrocytes. J Biol Chem 279: 35201-35209.

18. Srikrishna G, Nayak J, Weigle B, Temme A, Foell D, et al. (2010) Carboxylated $\mathrm{N}$-glycans on RAGE promote S100A12 binding and signaling. J Cell Biochem 110: 645-659.

19. Wang Y, Wang H, Piper MG, McMaken S, Mo X, et al. (2010) sRAGE induces human monocyte survival and differentiation. J Immunol 185: 1822-1835. 